\title{
Profile of Anaphylactic Reaction in Surabaya from January 2014 to May 2018
}

\author{
Amalia Putri Uswatun Hasanah ${ }^{1}$, Ari Baskoro ${ }^{2}$, Pesta Parulian ${ }^{3}$
}

${ }^{1}$ Faculty of Medicine, Universitas Airlangga, Surabaya, Indonesia.

${ }^{2}$ Department of Internal Medicine, Faculty of Medicine, Universitas Airlangga/Dr. Soetomo General Hospital, Surabaya, Indonesia. ${ }^{3}$ Department of Anaesthesiology and Reanimation, Faculty of Medicine, Universitas Airlangga, Surabaya, Indonesia.

\section{A B S T R A C T}

Introduction: Anaphylactic reaction is systemic hypersensitivity reaction. It is type 1 hypersensitivity reaction. The incidence can be mild to severe due to the sudden release of mediators by effector cells. This research aimed to examine the prevalence of anaphylactic reaction in Dr. Soetomo General Hospital in January 2014 until May 2018.

Methods: This study was a cross-sectional and retrospective study by assessing patients' medical records and was analyzed descriptively.

Results: 22 patients were identified as anaphylactic reaction. The prevalence of anaphylactic reaction from year to year cannot be identified surely because of underdiagnose and underreporting. The most common cause of anaphylactic reaction in Dr. Soetomo General Hsopital was drugs (50\%). The most drugs were antibiotics $(22.73 \%)$ and the most antibiotics were groups of penicillin $(40 \%)$ and cephalosporin (40\%). The most common clinical manifestation was skin-related $(77.27 \%)$, which includes urticaria $(4.55 \%)$, angioedem $(27.27 \%)$, pruritus $(27.27 \%)$ cold skin $(0.09 \%)$, pallor $(4.55 \%)$, and cyanosis $(4.55 \%)$. Most patients became better (45.54\%) after getting treatment from the doctor.

Conclusion: The most common cause of anaphylactic reaction was drugs, the most drugs were antibiotics and the most antibiotics were groups of penicillin and cephalosporin. The most clinical manifestation was skin-related. Most of anaphylactic reaction's patients became better after getting treatment from the doctor. Underdiagnose and underreporting are the problem often encountered in cases of anaphylactic reaction.

(c) 2020 JUXTA: Jurnal IImiah Mahasiswa Kedokteran Universitas Airlangga. Available at https://e-journal.unair.ac.id/juxta

* Correspondence: aribaskorodr62@gmail.com

JUXTA: Jurnal IImiah Mahasiswa Kedokteran Universitas Airlangga

p-ISSN: 1907-3623; e-ISSN: 2684-9453

DOI: 10.20473/juxta.V11122020.61-64

Open access under Creative Commons Attribution-ShareAlike 4.0 International License

(CC-BY-SA)

\section{ARTICLE INFO}

\section{Article history:}

Received 11 June 2020

Accepted 3 July 2020

\section{Keywords:}

Anaphylactic reaction,

Characteristics,

Clinical manifestations,

Drugs,

Antibiotics. 


\section{Introduction}

There is a medical term called Adverse Drug Reaction (ADR). The meaning of the term is an unwanted incident from a patient due to drug administration. Examples of ADR events are poisoning, drug allergies, and anaphylactic reactions. Anaphylactic reaction is included in type B ADR which means hypersensitivity related to immunological reactions. ${ }^{1}$ It is a systemic hypersensitivity reaction. The incidence can be mild to severe due to the sudden release of various mediators by effector cells. ${ }^{2}$ The symptoms shown are varied, including urticaria, respiratory problems, blood circulation, cardiovascular complications, nausea, vomiting, changes in body fluids, etc. ${ }^{3}$ There are various causes of anaphylactic reactions, including food, drugs, insect bites, vaccines, immunotherapy, and blood products. ${ }^{4}$ Drugs have a very important role in the emergence of anaphylactic reactions. Beta-lactam antibiotics, sulfa groups, aspirin, and non-steroidal antiinflammatory drugs are types of drugs that can cause anaphylactic reactions. ${ }^{5}$

From 1999 to 2010, there has been an epidemiological research related to anaphylaxis cases in the United States. This study obtained data from 2,458 patients with severe anaphylaxis, and from these data there were 1,446 cases of anaphylaxis deaths due to drugs. There were 1,078 cases in which types of medications that cause anaphylaxis could not be identified, while the remaining 368 could be identified. A total of 149 cases of anaphylaxis associated with antibiotics and penicillin became the main cause of this case. ${ }^{6}$

The literature states that the exact number of incidence of anaphylaxis from all triggers is still unknown. The difficulty to evaluate is due to lack of diagnosis (underdiagnoses) and the lack of reporting (underreported), as well as coding errors and the use of varying definitions of a related case. Nonetheless, it is clear that anaphylaxis was not uncommon, and the attack rate is increasing, especially in the first two decades of life. ${ }^{7}$ The description above shows a high incidence of anaphylactic reactions ${ }^{8}$, but problems such as those described above make the incidence of anaphylaxis difficult to evaluate. Therefore, this study aimed to examine the profile of anaphylactic reactions in Dr. Soetomo General Hospital from January 2014 to May 2018.

\section{Methods}

This study was a cross-sectional and retrospective study by assessing patients' medical record and was analyzed descriptively. Population in this research were all patients of anaphylactic reaction in Dr. Soetomo General Hospital from January 2014 to May 2018. The total sample were 22 patients. Thus, taking sample was conducted with non-probability sampling. The technique of non-probability sampling was total sampling.

Variables in this research were demographic aspects clinical manifestation, causes, and the final condition of patients after treatment of anaphylactic reactions. The data

were obtained through medical records. The data were entered into Microsoft Excel, collected based on each variable and analyzed descriptively. The data were performed in distribution tables and graphs.

\section{Results}

This research used descriptive method. Data used in the study came from secondary data, medical records of the patients hospitalized in Dr. Soetomo General Hospital who had anaphylactic reaction in the period of January 2014 to May 2018. The results of this study are presented in tables and graphs. This study contains data on demographics, cause of anaphylactic reactions, clinical manifestations, and the condition of the patient at the end of anaphylactic reaction after treatment. The number of medical records of the patients with anaphylactic reactions according to the ICD code of the anaphylactic reaction from January 2014 to May 2018 was 22 patients.

Table 1. Demographic Aspects of Rnaphylactic Reaction in Dr. Soetomo General Hospital from January 2014 to May 2018.

\begin{tabular}{|lll|}
\hline \multirow{2}{*}{ Sex } & \multicolumn{2}{c|}{ Age (\%) } \\
\cline { 2 - 3 } & $<15$ years old & $>\mathbf{1 5}$ years old \\
\hline Female & $1(25)$ & $11(68.75)$ \\
Male & $3(75)$ & $5(31.25)$ \\
Total & $4(20)$ & $16(80)$ \\
\hline
\end{tabular}

Table 2. Characteristics of patients presenting with anaphylaxis

\section{Characteristics}

No. of (\%)

\section{Causes}

Antibiotics

Penicillin

Generation III of

Cephalosporin

Quinolone

Unknown

Foods patients

Chemotherapy drugs

$5(22.73)$

$2(40)$

2 (40)

Blood components

$1(20)$

5 (22.73)

2 (9.09)

2 (9.09)

Anti-convulsion drugs

$2(9.09)$

Thrombolytic

$2(9.09)$

NSAID

$1(4.55)$

Post DCA

$1(4.55)$

1 (4.55)

Herbal

$1(4.55)$

\section{Clinical Manifestations}

\section{Cutaneous Features}

Pruritus

$6(27.27)$

Angioedema

$6(27.27)$

Cold acral

2 (9.09)

Pale

1 (4.55)

Urticaria

1 (4.55)

Cyanosis

1 (4.55)

Total

Respiratoty Features Dyspnoe
17 (77.27)

$9(40.91)$ 


\begin{tabular}{|ll|}
\hline Bronchospasm & $2(9.09)$ \\
Laryngeal edema & $1(4.55)$ \\
Total & $12(54.55)$ \\
Gastrointestinal Features & \\
Nausea & $2(9.09)$ \\
Vomitting & $2(9.09)$ \\
Abdominal cramp & $1(4.55)$ \\
Total & $5(22.73)$ \\
Cardiovascular Features & \\
Hypotension & $3(13.63)$ \\
Weak pulses & $1(4.55)$ \\
Total & $4(18.18)$ \\
Neurologic Features & \\
Dizziness & $1(4.55)$ \\
Convulsion & $1(4.55)$ \\
Headache & $1(4.55)$ \\
Total & $3(13.64)$ \\
Others & \\
Unknown & $5(22.73)$ \\
Total & $5(22.73)$ \\
Final Condition & \\
Recover & $10(45.45)$ \\
Died & $2(9.09)$ \\
Forced home & $2(9.09)$ \\
Unknown & $8(36.36)$ \\
\hline
\end{tabular}

\section{Discussion}

\section{Demographic Aspects}

Based on the data on sex distribution based on age group, most patients at age $<15$ years old were male $(75 \%)$, while at age $>15$ years old the most sufferers were women $(68.75 \%)$. This data is in accordance with the literature which stated that in a study in one of the primary health care centers in the United Kingdom (UK), there were differences in the frequency between male and female for the incidence of anaphylaxis. At the age of 10-15 years old, male are more often affected by anaphylactic reactions, whereas at the age of $>15$ years old, female are more often affected by anaphylactic reactions. ${ }^{8}$

The difference in sex distribution to age is influenced by IgG4 antibodies. IgG4 antibodies block antigens, thus antigens cannot bind to IgE on mast cells. In a study, 172 healthy adult men had higher lgG4 concentrations than women. It is used as a defense mechanism to fight allergies in adult men. ${ }^{9}$

There are also studies that discuss the association of hormones with allergic reactions. Sex hormone receptors are found on the surface of lymphocytes, monocytes, and mast cells. Estrogen in women has the effect of triggering a humoral immune response, one of which is an allergic reaction because estrogen can increase mast cell reactivity and can reduce the number of allergens needed to induce allergic symptoms. Whereas testosterone in men works against sensitization. ${ }^{9}$

\section{Cause of Anaphylactic Reactions}

The results of the study on the percentage of causes of anaphylactic reactions found that the most common cause was related to drugs, namely 11 patients from 22 total patients $(50 \%)$. The most drugs were due to antibiotics, which was as many as 5 patients $(22.73 \%)$. From the results of the research that the author got from the medical records of Dr. Soetomo General Hospital, there were 3 groups that caused anaphylactic reactions, including penicillin antibiotics in 2 patients (40\%), 3rd generation cephalosporin antibiotics in 2 patients (40\%), and quinolone group antibiotics in 1 patient $(20 \%)$. This is consistent with the literature which stated that in a 10-year study (1992-2001) in the UK there were 88 cases (44\%) of anaphylactic reactions associated with drugs, 47 cases associated with insect sting (23\%), 45 cases associated with foods $(22 \%), 18$ cases associated with possible food $(9 \%)$, and 4 associated with others (2\%). ${ }^{10}$

Antibiotics generally do not directly stimulate the immune system, because of the small size of the molecule. However, the size of these small molecules can bind with larger molecules to create hapten-carrier complexes. Penicillin has a tendency to induce various types of immune-mediated hypersensitivity reactions. After $\beta$ lactam ring is open, it can bind to lysine to create a major determinant of allergic sensitivity, namely the penicilloylprotein complex. ${ }^{11}$ All natural and semisynthetic forms of penicillin can cause allergies but are more commonly seen after parenteral administration than oral. ${ }^{12}$ Penicillin crossreact with other semisynthetic penicillin including monobactams and carbapenems, and can also cross-react with other antibiotics such as cephalosporins. ${ }^{13}$

\section{Clinical Manifestation}

Based on the literature, skin involvement is reported at $80 \%$ to $90 \%$, meaning that skin involvement is the most common condition in patients with anaphylactic reactions. Skin involvement in question includes urticaria, swollen lips, tongue, uvula/palate, and pruritus (16). This is in accordance with the results of a research which showed that skin involvement had the highest rates of 17 patients $(77.27 \%)$ and neurological involvement had the lowest number as 3 patients (13.64\%). Skin involvement included pruritus in 6 patients $(27.27 \%)$, angioedema in 6 patients $(27.27 \%)$, cols acral in 2 patients $(9.09 \%)$, pale in 1 patient (4.55\%), and urticarial in 1 patient (4.55\%).

In addition, the author also obtained literature regarding anaphylactic reactions performed in Korea. In this study, there were 2,682 cases out of 55,432 people reported as ADE/Adverse Drug Reactions (4.84\%). Among the many cases of hypersensitivity reactions due to drugs, there were $70 \%$ of patients showing clinical manifestations in the skin. ${ }^{1}$

\section{The Final Condition of Patients after Treatment of Anaphylactic Reactions}

Most patients improved after treatment, which were as many as 10 patients. The other conditions were 2 patients passed away (9.09\%), 2 patients were forced home $(9.09 \%)$, and 8 patients with unknown reason $(36.36 \%)$. This is consistent with the literature that stated that deaths from anaphylaxis are considered rare. ${ }^{7}$ 


\section{Conclusion}

The most common cause of anaphylactic reactions was related to drugs (50\%). The most drugs were due to antibiotics in 5 patients (22.73\%). The most antibiotics that caused anaphylactic reactions were penicillin (40\%) and cephalosporin groups (40\%). The most clinical manifestations of anaphylactic reactions were those associated with the skin $(77.27 \%)$, and the least is neurological involvement (13.64\%). Most patients improve after treatment $(45.45 \%)$.

\section{CONFLICT OF INTEREST}

The author stated there is no conflict of interest in this study.

\section{REFERENCES}

1. Thong BYH and Tan T-C. Epidemiology and Risk Factors for Drug Allergy. Br J Clin Pharmacol. 2011; 71: 684-700.

2. Dhami S, Sheikh A, Muraro A, et al. Quality Indicators for the Acute and Long-Term Management of Anaphylaxis: A Systematic Review. Clinical and Translational Allergy. 2017; 7: 15.

3. Kim SY, Kim MH and Cho YJ. Different Clinical Features of Anaphylaxis according to Cause and Risk Factors for Severe Reactions. Allergology International : Official Journal of the Japanese Society of Allergology. 2018; 67: 96-102.

4. Wawrzyniak $P$, Akdis CA, Finkelman FD and Rothenberg ME. Advances and Highlights in Mechanisms of Allergic Disease in 2015. The Journal of Allergy and Clinical Immunology. 2016; 137: 1681-96.
5. Park HK, Kang MG, Yang MS, Jung JW, Cho SH and Kang HR. Epidemiology of Drug-Induced Anaphylaxis in a Tertiary Hospital in Korea. Allergology International : Official Journal of the Japanese Society of Allergology. 2017; 66: 557-62.

6. Jerschow E, Lin RY, Scaperotti MM and McGinn AP. Fatal Anaphylaxis in the United States, 1999-2010: Temporal Patterns and Demographic Associations. The Journal of Allergy and Clinical Immunology. 2014; 134: 1318-28.e7.

7. Simons FE. Anaphylaxis: Recent Advances in Assessment and Treatment. The Journal of Allergy and Clinical Immunology. 2009; 124: 625-36; quiz 37-8.

8. Tejedor-Alonso MA, Moro-Moro M and Múgica-García MV. Epidemiology of Anaphylaxis: Contributions From the Last 10 Years. Journal of Investigational Allergology \& Clinical Immunology. 2015; 25: 163-75; quiz follow 74-5.

9. Afify SM and Pali-Schöll I. Adverse Reactions to Food: The Female Dominance - A Secondary Publication and Update. World Allergy Organ J. 2017; 10: 43-.

10. Liew WK, Williamson E and Tang ML. Anaphylaxis Fatalities and Admissions in Australia. The Journal of Allergy and Clinical Immunology. 2009; 123: 434-42.

11. Legendre DP, Muzny CA, Marshall GD and Swiatlo E. Antibiotic Hypersensitivity Reactions and Approaches to Desensitization. Clinical Infectious Diseases : An Official Publication of the Infectious Diseases Society of America. 2014; 58: 1140-8.

12. Bhattacharya S. The Facts about Penicillin Allergy: A Review. J Adv Pharm Technol Res. 2010; 1: 11-7.

13. Justiz Vaillant $A A$ and Zito PM. Immediate Hypersensitivity Reactions. StatPearls. Treasure Island (FL): StatPearls Publishing Copyright (C) 2020, StatPearls Publishing LLC., 2020 